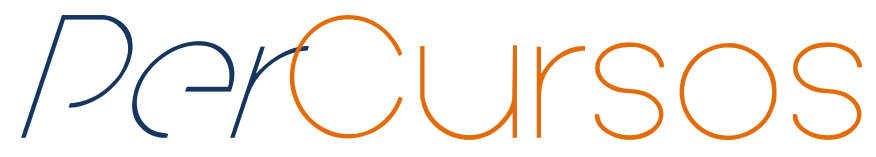

\title{
A perspectiva enunciativista e a prática de análise linguística: encaminhamentos de ordem metodológica
}

\begin{abstract}
Resumo
Este artigo tem como objetivo discutir questões relacionadas a um dos eixos norteadores da disciplina de Língua Portuguesa, a análise linguística, que, vinculada aos eixos de leitura, escrita e oralidade, apresenta particularidades significativas para uma efetiva apropriação da língua nos processos de ensino e aprendizagem. A discussão busca, dessa forma, compreender as contribuições da perspectiva enunciativista para o trabalho com análise linguística, e, para materializar tal proposta, apresentamos uma atividade de análise a partir de uma crônica - considerando os fundamentos bakhtinianos, buscamos robustecer a literatura da área da educação linguística, embasando-nos, para isso, nas teorizações de Geraldi (2003 [1991]); Antunes (2003); Mendonça (2006) e Cerutti-Rizzatti; Cassol Daga e Catoia Dias (2014).
\end{abstract}

Palavras-chave: Análise Linguística. Língua Portuguesa. Processos de Ensino e Aprendizagem.

\author{
Amanda Machado Chraim \\ Doutoranda em Linguística \\ Aplicada na Universidade Federal \\ de Santa Catarina - UFSC. \\ Brasil \\ amchraim@hotmail.com
}

\section{Suziane da Silva Mossmann}

Doutoranda em Linguística

Aplicada na Universidade Federal de Santa Catarina - UFSC.

Brasil

suzismossmann@gmail.com

\section{Para citar este artigo:}

CHRAIM, Amanda Machado; MOSSMANN, Suziane da Silva. A perspectiva enunciativista e a prática de análise linguística: encaminhamentos de ordem metodológica. Revista PerCursos, Florianópolis, v. 18, n.37, p. 151 - 175, maio/ago. 2017.

\section{DOI: $10.5965 / 1984724618372017151$}

http://dx.doi.org/10.5965/1984724618372017151 


\title{
The utterer-centered approach and the practice of linguistic analysis: methodological suggestions
}

\begin{abstract}
This article aims to discuss issues related to one of the guiding principles in Portuguese language subject, namely linguistic analysis, which, when associated with reading, writing and speaking principles, presents noteworthy particularities for an effective appropriation of the language in learning and teaching processes. Discussion aims to, thus, to understand the contributions of enunciative perspective to the work done with linguistic analysis, and, to bring such a proposal to life, we have presented an analysis activity based on a chronicle - taking into consideration Bakhtinian principles, we have tried to strengthen the literature in the linguistic education area, based on the theories of Geraldi (2003 [1991]); Antunes (2003); Mendonça (2006) and Cerutti-Rizzatti; Cassol Daga and Catoia Dias (2014).
\end{abstract}

Keywords: Linguistic Analysis. The Portuguese Language. Learning and Teaching Processes. 


\section{Introdução}

Os intensos debates abrangendo o trabalho com a língua portuguesa em sala de aula são objeto de atenção de pesquisadores e professores tanto na esfera escolar quanto na esfera acadêmica desde meados da década de 1980. Entretanto, ainda que não se possa generalizar, de um lado, apresentam-se os conhecimentos científicos relativos à compreensão dos modos de conceber a língua e os sujeitos em relação e as implicações metodológicas de uma ancoragem teórico-epistemológica pautada no ideário históricocultural, em uma perspectiva dita inovadora, ou, ainda, em outras concepções cujas denominações oscilam entre uma abordagem conciliadora e conservadora (com base em BEZERRA; REINALDO, 2013); enquanto, do outro lado, professores em percurso de formação inicial ou continuada buscam dar conta das diferentes perspectivas relativas ao trabalho com a língua em contextos nos quais há uma abordagem imprecisa do que tanto já foi discutido acerca das concepções norteadoras do trabalho docente em sala de aula (BRITTO, 1997).

Diante de tais considerações, apesar de muito se discutir a respeito do trabalho com a língua em uma dimensão operacional e reflexiva, é consenso entre pesquisadores e professores que os modos de se lidar com os eixos de ensino e de aprendizagem apresentados nos Parâmetros Curriculares Nacionais (PCNs), especialmente no que tange à análise linguística, ainda carecem de aprofundamento teórico e metodológico. Diferentes ancoragens norteiam, em nosso entendimento, determinadas ações metodológicas, sendo fundamental, nessas circunstâncias, que se compreendam as implicações de se assumir uma prática de ensino centrada na palavra, na oração ou no texto-enunciado.

Assim, trabalhar com a análise linguística em favor da leitura, da produção de textos orais e escritos, bem como da escuta implica mais do que uma nova definição do que seria o estudo da gramática, conforme problematiza Geraldi (2003 [1991]). A mudança de concepção de sujeito e de língua abrange um posicionamento teóricoepistemológico convergente com uma compreensão de que o estudo da língua na escola transcende categorizações tomadas de modo abstrato, em um contexto em que as 
atividades metalinguísticas antecedem e prevalecem sobre as atividades linguísticas e epilinguísticas (GERALDI, 2003 [1991]).

Tal cenário, no plano teórico, já se coloca como amplamente discutido, uma vez que nas últimas décadas as pesquisas realizadas na área da Linguística Aplicada vêm colocando sob suspeição práticas e entendimentos atinentes ao trabalho com a língua em sala de aula (a exemplo de dissertações realizadas no Núcleo de Estudos em Linguística Aplicada da Universidade Federal de Santa Catarina, TOMAZONI, 2012; CATOIA DIAS, 2012; CORREIA, 2013; GIACOMIN, 2013). No entanto, apesar das variadas publicações e trabalhos relativos a essas questões envolvendo o fazer docente e sua ancoragem teórica, determinados conhecimentos pautados na experiência escolar dos professores costumam ser frequentemente um norteador mediante a realidade do trabalho em sala de aula, o que se torna uma problemática bastante complexa e que exigiria espaço mais substancial para que pudéssemos, de fato, abordar um conjunto de fatores relacionados a tal movimento por parte do corpo docente em muitas escolas.

Desse modo, mediante tal cenário, optamos por delimitar nossa discussão à busca por compreender possíveis contribuições da perspectiva enunciativista, considerando os fundamentos do pensamento do Círculo de Bakhtin, para uma educação linguística comprometida com os pressupostos de um ideário que se entende históricocultural. Importa-nos, assim, partir de uma breve contextualização das discussões envolvendo as diferentes acepções atinentes ao conceito de análise linguística e, para isso, focalizaremos especialmente as abordagens de Geraldi (2003 [1991]); Antunes (2003) e Mendonça (2006); em seguida, tomaremos a perspectiva enunciativista no que tange aos fundamentos do pensamento do Círculo de Bakhtin e, enfim, apresentaremos encaminhamentos metodológicos de uma análise linguística empreendida em favor da leitura, da escuta e da produção de textos orais e escritos com base em Cerutti-Rizzatti; Cassol Daga e Catoia Dias (2014). 


\section{Análise linguística: perspectivas}

Numa tentativa de situar as diferentes abordagens em favor da análise linguística, e reconhecendo que sob esse rótulo há perspectivas distintas acerca do fazer pedagógico relacionado ao ensino da língua portuguesa, Bezerra e Reinaldo (2013) registram que já a partir dos anos 1970 o termo análise linguística passa a conviver com o de descrição linguística no cenário acadêmico do Brasil; no entanto, nesse momento, havia uma tendência para analisarem-se as unidades menores da língua - a palavra, o sintagma, a frase. É, então, a partir da década de 1980, com a Linguística se debruçando sobre os aspectos relacionados aos processos de ensino e aprendizagem de língua portuguesa, que a análise linguística passa a se sobrepor. Entre as décadas de 1980 e 1990, o foco volta-se para o componente linguístico do texto, e a partir dos anos 1990 o estudo desse componente passa a ser associado ao funcionamento do gênero, tomado como materialização do discurso (BEZERRA; REINALDO, 2013). O termo análise linguística começa a ser utilizado, assim, nesse momento, para “[...] denominar uma nova perspectiva de reflexão sobre o sistema linguístico e sobre os usos da língua, com vistas ao tratamento escolar de fenômenos gramaticais, textuais e discursivos" (MENDONÇA, 2006, p. 205).

Tornando-se, pois, um dos eixos de ensino indicados pelos Parâmetros Curriculares Nacionais, a análise linguística passou a ser foco de produções paradidáticas, no entanto, por algum tempo, e ainda hoje há resquícios disso, este é um eixo norteador que gera incompreensões por parte dos professores de Língua Portuguesa, já que é tomado, ao mesmo tempo, por diferentes fundamentos teóricos, como sinônimo de “conhecimentos gramaticais" ou de "conhecimentos linguísticos" ou até mesmo de “normas” (BEZERRA; REINALDO, 2013). Tal flutuação no que se refere a uma definição precisa do conceito incide, pois, para uma instabilidade em relação ao fazer pedagógico voltado ao eixo de análise linguística. Bezerra e Reinaldo (2013) corroboram tal olhar quando apontam que, enquanto os eixos de leitura e de escrita são trabalhados com embasamento nas teorias enunciativistas, o estudo dos componentes linguísticos é subsidiado pela norma num viés descritivo, sem estabelecer, muitas vezes, relação com o plano textual e enunciativo. Assim, enquanto nos processos de leitura e de escrita se 
materializa uma perspectiva de ensino como conhecimento e produção, no plano da análise linguística ainda há um ensino pautado somente no reconhecimento (com base em GERALDI, 2003 [1991]).

Bezerra e Reinaldo (2013) observam três tendências relacionadas aos estudos das unidades da língua, que denominam de conservadora, conciliadora e inovadora. A tendência conservadora é aquela que, segundo as autoras, coloca em primeiro plano os conhecimentos da gramática tradicional num viés descritivo e prescritivo. O texto, nessa perspectiva, aparece como pretexto para o reconhecimento do elemento gramatical em foco, e não para leitura e construção de sentidos - as atividades realizadas consistem em retirar dele um fragmento para indicar suas classes ou categorias morfossintáticas (ANTUNES, 2010). A língua, nesse contorno, parece ser tomada como um sistema do qual o sujeito se apropria para usá-la a partir de necessidades específicas (GERALDI, 2003 [1991]). O que está em jogo aqui, de acordo com Antunes (2003), é a pretensão de que o aluno passe a saber os nomes que os aspectos da língua têm, reconhecendo-os, rotulando-os, nomeando-os. Numa crítica a essa abordagem, Mendonça (2006, p. 203) registra que o objetivo da escola não é formar gramáticos ou linguistas descritivistas, mas sim sujeitos capazes de agir verbalmente de forma autônoma, levando em conta as diferentes situações de interação a que podem se engajar:

O isolamento de unidades mínimas [...] é um procedimento de análise e que só tem razão se retornar ao nível macro: na escola, analisar o uso de determinada palavra num texto só tem sentido se isso trouxer alguma contribuição à compreensão do funcionamento da linguagem e, portanto, se auxiliar a formação ampla dos falantes.

Na segunda tendência, a conciliadora, estão aquelas teorias advindas tanto da Linguística quanto da tradição gramatical, numa conciliação entre o tradicional e o moderno (BEZERRA; REINALDO, 2013). As práticas de ensino de língua portuguesa revelam - e sempre revelaram -, segundo Mendonça (2006), uma "mescla" de perspectivas, com a forma tradicional de ensino de gramática concorrendo com novas práticas. A autora chama atenção para o fato de que aliar uma nova perspectiva com 
outras já conhecidas no processo de ensino é natural no decurso da apropriação dos docentes de uma proposta teórica e metodológica distinta daquela da sua prática cotidiana. "Nesse sentido, atravessamos um momento especial, em que convivem ‘velhas' e 'novas' práticas no espaço da aula de gramática, por vezes, conflituosas” (MENDONÇA, 2006, p. 201).

Na tendência inovadora, por outro lado, é perceptível a contribuição da Linguística nas denominações para o estudo da língua - o objetivo, pois, desse estudo, é o desenvolvimento da leitura por parte dos alunos, de forma que não há uma sistematização de temas e atividades a eles relacionadas (BEZERRA; REINALDO, 2013). Ao tratarem da dimensão textual e discursiva dos textos, apontam Bezerra e Reinaldo (2013, p. 61), nessa tendência fica em segundo plano o ensino sistemático das unidades linguísticas, apontando para uma posição polarizada acerca da didatização da análise linguística: "[...] Essa ausência de estudo metalinguístico denuncia a compreensão de que é desnecessária a superordenação das unidades linguísticas resultante de uma perspectiva teórica, sobretudo a da gramática tradicional”. Mendonça (2006), num outro olhar, chama atenção para o fato de que a análise linguística não exclui a gramática das salas de aula, já que não seria possível utilizar a língua ou refletir sobre ela, tendo em vista que “[...] não existe língua sem gramática [...]” (ANTUNES, 2003, p. 85). A análise linguística engloba, assim, os estudos gramaticais, entre outros aspectos, mas num viés distinto, pois os objetivos a serem alcançados são outros.

A análise de Bezerra e Reinaldo (2013) em relação a essas tendências importa-nos na medida em que podemos perceber indícios sobre a forma com que o eixo de análise linguística vem sendo delineado nas aulas de língua portuguesa. As autoras entendem, pois, que a concepção de análise linguística como um conjunto de atividades epilinguísticas e metalinguísticas ${ }^{1}$ aparece ancorada por vezes na tradição gramatical, por vezes nas teorias linguísticas e em alguns casos na combinação dessas duas perspectivas.

\footnotetext{
${ }^{1}$ Geraldi (2003 [1991]) diferencia níveis distintos de reflexão em relação às ações que se fazem com e sobre a linguagem, e para isso traz o conceito de atividades epilinguísticas e metalinguísticas. As primeiras correspondem àquelas atividades praticadas nos processos de interação, referindo ao assunto em pauta "[...] resultam de uma reflexão que toma os próprios recursos expressivos como seu objeto [...]" (GERALDI, 2003 [1991], p. 23). As atividades metalinguísticas, por outro lado, “[...] são aquelas que tomam
} 
No que se refere às elaborações teóricas advindas da academia, que incidem no fazer pedagógico dos docentes, a mudança de foco sobre o estudo da língua resulta, como já exposto, de um debruçar-se da Linguística sobre os processos de ensino e aprendizagem da leitura e da escrita nas aulas de Língua Portuguesa. Assim, como registram Bezerra e Reinaldo (2013, p. 51), a preocupação passa a ser a de "[...] atender à diversidade de usos em função das necessidades comunicativas (inclusive as que requerem a norma padrão)", ao invés do foco anterior, que era o de "[...] atender à norma padrão estabelecida [...]”.

Geraldi (2003 [1991]) propõe, assim, que o eixo da análise linguística deve partir tanto do processo de produção de textos dos próprios alunos quanto do processo de leitura - em sua primeira abordagem sobre este tema, o autor coloca como objetivo essencial da análise linguística a reescrita do texto do aluno, para que, dessa forma, ele possa refletir sobre os fenômenos gramaticais, textuais e discursivos que perpassam os usos linguísticos (MENDONÇA, 2006). Dessa forma, partindo do erro para a autocorreção, Geraldi (2003 [1991]) sugere que o professor foque em apenas um problema relevante de cada vez, para que seja reescrito com a orientação do docente.

Comparando, transformando, experimentando novos modos de construção sobre a linguagem - práticas relacionadas às atividades epilinguísticas -, abre-se a possibilidade para o trabalho de sistematização, nascendo então as atividades metalinguísticas: “[...] a partir do conhecimento sobre os fatos relevantes da língua, pode-se criar hipóteses sobre a natureza da linguagem, descrevê-la em um quadro nocional, usando-se a língua para falar dela mesma [...]” (BEZERRA; REINALDO, 2013, p. 36). O trabalho com análise linguística, assim, deve partir, de acordo com Mendonça (2006), de uma reflexão explícita e organizada para, então, produzir-se progressivamente conhecimentos e categorias explicativas dos fenômenos analisados - dessa maneira, o aluno irá se apropriar, gradualmente, de um quadro teórico que permitirá que descreva sua própria língua

a linguagem como objeto não mais enquanto reflexão vinculada ao próprio processo interativo, mas conscientemente constroem uma metalinguagem sistemática com a qual falam sobre a língua" (GERALDI, 2003 [1991], p. 25). Dados esses apontamentos, entendemos, pois, que, por conta de tais conceitos já terem sido explorados de forma ampla pela literatura da área, não se torna relevante uma retomada mais aprofundada de ambos para as finalidades deste artigo. 
(SILVA, 2010). A análise linguística, como aponta Silva (2010), configura-se, então, como um eixo de trabalho na escola que tem a linguagem e seu uso como ponto de partida e de chegada. Com uma ação docente embasada nessa perspectiva, o aluno passará a ter "[...] condições de compreender como a língua funciona, como é organizada em textos, como elementos gramaticais servem para ligar palavras, frases, parágrafos, exercitando, dessa forma, a linguagem em diferentes contextos" (MARCHIORO, 2010, p. 14).

Filiada a uma perspectiva que privilegia o texto como objeto de ensino, Antunes (2003, p. 111, grifos da autora) registra que “[...] toda atividade linguística é necessariamente textual", e propõe, dessa forma, que o eixo de análise no ensino de língua portuguesa deve ser centrado naqueles elementos que são determinantes para a construção da sua textualidade. Distanciando-se, assim, de uma prática de análise que seja mera identificação de categorias gramaticais, as teorias da Linguística Textual que se voltam ao ensino advogam em favor de práticas que busquem desenvolver a compreensão acerca dos elementos que, para além do gramatical, são imprescindíveis para o entendimento do texto (ANTUNES, 2010). Para dar conta disso, categorias eminentemente textuais são apontadas como necessárias para o ensino e aprendizagem da língua, como, por exemplo, os critérios de coesão, de coerência e de relevância, tudo isso a partir de situações concretas de uso. Importa esclarecer, contudo, que tais critérios não são isolados dos demais, de forma que os aspectos globais do texto estão intrinsecamente ligados aos pontuais, ao seu léxico e gramática, já que, de acordo com Antunes (2010, p. 18), não há possibilidade de “[...] dar conta dos sentidos do texto, dos recursos de sua construção ou de sua adequação vocabular, sem recorrer à consideração de itens da gramática". Com a análise nesses contornos que, segundo a autora, deve ser reiterada e consistente, o objetivo é o de desenvolver nos alunos em fase de aprendizagem a percepção e a identificação dos fenômenos relacionados ao texto, organizando um planejamento pautado em conteúdos que tenha como objetivos de ensino e de aprendizagem a compreensão e ampliação do repertório cultural dos sujeitos, de modo a facultar uma atuação ressignificada dos diferentes usos da língua falada e escrita, considerando as compreensões de mundo materializadas nesses mesmos usos. 
Compreendemos que Antunes (2003; 2010), calcada nas teorias da Linguística Textual, fundamenta uma prática pedagógica de análise textual - com a própria nomenclatura já apontando para um foco exclusivo no texto -, complementa de forma substancial as produções teóricas de autores como Geraldi (2003 [1991]) e Mendonça (2006), mesmo que embasados em perspectivas teóricas distintas, no que se refere ao trabalho com a análise linguística nas aulas de Língua Portuguesa.

Importa-nos, agora, para dar conta daquilo que propomos neste artigo, trazer os conceitos do pensamento do Círculo de Bakhtin que ancoram a discussão que temos empreendido acerca do trabalho com a linguagem na escola e, mais especificamente, do desenvolvimento de um dos eixos de trabalho, a análise linguística sob a ótica da perspectiva enunciativista. Para tanto, faremos emergir uma reflexão a partir do que é língua(gem) nesse viés, pois assumir determinada concepção implica na definição daquilo que é relevante ser objeto de ensino e aprendizagem nas escolas.

\section{Fundamentos do pensamento do círculo de Bakhtin}

Compreender a análise linguística a partir de um viés histórico-cultural implica, nesses termos, lançar mão de uma ancoragem teórico-epistemológica convergente com a proposição de que os sujeitos historicamente situados vivem, interagem e agem no mundo por meio da língua, tomada como lugar de interação, de constituição dos sujeitos e dela própria, considerando os fundamentos bakhtinianos; e como instrumento psicológico de mediação simbólica, tomando por base o pensamento vigotskiano. Desse modo, propor outra forma de conceber a análise linguística é atentar para ressignificações relativas ao trabalho com a língua a partir de uma ação docente que não denegue o papel do sistema de formas linguísticas, mas que também não o considere central a ponto de que se tomem as ações metalinguísticas como eixo da aula de Língua Portuguesa, ignorando as inconsistências de se propor um trabalho pautado no esvaziamento do sentido da língua, o qual se situa para além da frase e da oração, para além das microunidades de significado, estando também nestas, mas fundamentalmente no tensionamento entre a dimensão verbal e extraverbal do enunciado proferido por 
determinados interlocutores, em um tempo e espaço específico, tomando por base projetos de dizer também situados e, portanto, únicos e irrepetíveis (VOLOCHÍNOV, 2013 [1930]).

Nesse contexto, o trabalho com análise linguística mediante tais proposições assume um status teórico-metodológico (GERALDI, 2006 [1984]), para o qual tomamos como base os fundamentos do pensamento do Círculo de Bakhtin, visando compreender as contribuições de tais conceitos para um olhar para a linguagem ancorado na perspectiva enunciativista. Assim, partimos do que Volóshinov (2009 [1929]) discute acerca da natureza interacional da linguagem como um fenômeno de duas faces cujos referentes encontram-se no eu e no outro. A relação entre os sujeitos em uma dimensão situada no que concerne aos horizontes organizadores dos modos sociais de dizer constitui a realidade fundamental da língua nessa perspectiva. Para Volóshinov (2013 [1930]), a língua precisa ser considerada em relação às questões políticas, sociais e econômicas da sociedade, ao intercâmbio comunicativo social, à interação verbal propriamente dita no que se refere às enunciações e às formas gramaticais da língua.

O autor ainda apresenta uma articulação entre dimensão verbal e extraverbal, considerando o auditório social e a situação em que os sujeitos lançam mão de tipos relativamente estáveis de enunciados para dar conta dos seus projetos de dizer. Importa enfatizar que o signo verbal assume sentidos conforme a interação estabelecida entre interlocutores no que tange ao conteúdo temático dos dizeres, em um determinado tempo e espaço, considerando valores e crenças em negociação. O sentido, de acordo com Volóshinov (2009 [1929]), refere-se ao processo de significação da palavra tomada na cadeia discursiva e ideológica, de modo que o signo passa a representar uma realidade a partir do olhar e da interpretação dos interlocutores que materializam seus projetos de dizer por meio de uma determinada forma linguístico-discursiva.

Os temas da dialogia como simpósio universal do existir humano (FARACO, 2007) e da responsabilidade do ato de se enunciar nesse caldeirão heteroglóssico de vozes constituem-se como fundamentais para a compreensão de uma linguagem que se pensa e que é pensada a partir da intensa negociação de sentidos entre valorações e interpretações de mundo dos sujeitos que se situam em contextos específicos. Para 
Bakhtin (2010 [1920-24]), viver, nesse sentido, é tomar posição, é agir por meio da língua no mundo como sujeito singular, responsável e respondente, não se eximindo da responsabilidade única de assumir o lugar de onde se pensa e se intervém no mundo.

Nessas circunstâncias, importa enfatizar que a singularidade do sujeito e a irrepetibilidade das enunciações desses mesmos sujeitos são concebidas na tensão entre subjetividade e alteridade, uma vez que é na interação que os sujeitos se constituem, ressignificam suas compreensões e, assim, modificam os modos de se enunciar na vida. Para Geraldi (2010), esta é uma das questões fundamentais na compreensão do sujeito tomado a partir dos fundamentos bakhtinianos, a incompletude fundante de cada ser e a necessidade de um excedente de visão que nos transcende coloca o sujeito em condição de constante busca e de constituição de si, não havendo soberania de um sujeito em relação ao outro. A responsabilidade do ato de dizer chama-nos a responder de modo único, ainda que essa unicidade se configure como parte do caldeirão de vozes que constitui nossa consciência no que tange às forças centrípetas e centrífugas atinentes à materialização de nossos posicionamentos por meio da língua.

De acordo com Volochínov (2013 [1930]), usar a língua é usá-la na vida e a enunciação para ele refere-se à expressão material do sentido, de modo que se organiza em relação à situação social e ao auditório. A enunciação de cada sujeito, nesses termos, conta com a entonação, cujo papel volta-se para a articulação entre a enunciação, a situação e o auditório, expressando, dessa maneira, a valoração social. O autor ainda menciona como constitutiva da enunciação a seleção de palavras e a disposição delas no interior do enunciado, estando ambas relacionadas à situação social e ao auditório. Bakhtin (2010 [1952-53]), no que concerne ao enunciado, caracteriza-o como unidade real da comunicação discursiva, considerando sua configuração a partir da alternância dos sujeitos que emolduram o enunciado, e da conclusibilidade, a qual se refere ao tratamento exaustivo do tema, aos limites do projeto discursivo e à situação de interação atinente às formas típicas composicionais. O enunciado é tomado ainda na relação valorativa estabelecida entre os sujeitos e o conteúdo semântico-objetal.

Para Bakhtin (2010 [1952-53]), aprender a usar a língua é aprender a construir enunciados em conformação com a esfera da atividade humana, de acordo com as 
condições específicas de uso. Nesse contexto, os gêneros organizam o nosso modo de dizer a partir da relação do ato de dizer dos sujeitos singulares em interação no que respeita ao conteúdo temático, ao estilo e à composição. Nesses termos, o gênero funciona como uma espécie de baliza que orienta a produção do enunciado no que se refere ao objeto e à finalidade do projeto de dizer do qual os sujeitos lançam mão, à seleção dos procedimentos composicionais para organização, disposição e acabamento da totalidade discursiva e ao estilo, considerando a escolha dos recursos lexicais, gramaticais e fraseológicos. O autor entende que o estudo da linguagem requer que se considere um estreito e indissociável vínculo entre seu uso e a atividade humana, o que significa que o agir humano não se dá fora da interação, nem o dizer fora do agir (FARACO, 2009). Tal compreensão complexifica o estudo da linguagem, de modo que, ao se pensar em uma discussão de análise linguística, é imprescindível levar em conta que os usos da linguagem se dão sempre em situações comunicativas específicas, estando relacionados às esferas da atividade humana, ao tempo-espaço em que se dão e ao suporte, de maneira que os sentidos construídos nos projetos de dizer modifiquem-se mediante alteração de algum desses elementos.

A relativa estabilidade dos enunciados que constituem os gêneros abarca, nessas condições, o movimento da historicidade e das modificações acrescidas pelos sujeitos por conta da unicidade e eventicidade implicada em cada uso. Não se abre mão da referência ao passado, à história, ao dado, mas não é possível pensar que os sentidos não se alterem ao longo do tempo, justamente por conta do estreito vínculo entre linguagem e atividade humana. Para Bakhtin (1997, p. 106, grifos do autor),

O gênero sempre é e não é o mesmo, sempre é novo e velho ao mesmo tempo. O gênero renasce e se renova em cada nova etapa do desenvolvimento [...] e em cada obra individual de um dado gênero. Nisto consiste a vida do gênero. [...] O gênero vive do presente mas sempre recorda o seu passado, o seu começo. É o representante da memória criativa no processo de desenvolvimento literário. É precisamente por isto que tem capacidade de assegurar a unidade e a continuidade desse desenvolvimento. 
Há, nesses termos, uma ampliação da discussão acerca da linguagem, uma vez que, considerando a esfera da atividade humana e as relações estabelecidas nessas esferas, temos diferentes modos de organizar os enunciados e de dar forma e vida a eles. A relação entre estabilidade e instabilidade articula-se, assim, a questões que transcendem a língua em sua natureza sistêmica. Há, de acordo com Bakhtin (2010 [195253]), usos considerados mais padronizados e usos mais suscetíveis a mudanças, o que não quer dizer que para os primeiros a mudança não se faça presente, nem que para os segundos a padronização não seja elemento constitutivo deles, uma vez que a tensão estabelecida se dá por conta das relações humanas organizadas em uma atmosfera de forças centrípetas em embate com forças centrífugas.

A heterogeneidade dos gêneros torna pouco viável uma classificação precisa dos diferentes modos de dispor o dizer. Bakhtin (2010 [1952-53]) propõe apenas, nessas circunstâncias, uma organização relativa à ideologia oficial e do cotidiano, que toma determinados usos como primários e outros como secundários. Como temos discutido, a partir dos fundamentos do Círculo de Bakhtin, o dizer não se dá fora do gênero e as diferentes esferas e organizações sociais, políticas e econômicas constituem modos mais elaborados em relação à aposição de vozes atreladas aos sistemas oficiais, o que não quer dizer que não haja uma tensão dialética estabelecida a partir das ideologias do cotidiano (VOLÓSHINOV, 2009 [1929]). Concebem-se, assim, os gêneros primários como mais vinculados a questões da vida social íntima no que se refere à relação com contextos mais imediatos, tais como conversas familiares, telefonemas, mensagens via dispositivos eletrônicos, bilhetes. Já os gêneros secundários relacionam-se às esferas atreladas a atividades que materializam modos de dizer e de agir objetificados a partir de sistemas filosóficos, científicos, éticos e estéticos. Podemos mencionar, nesses termos, gêneros relacionados à esfera acadêmica, jornalística, literária, entre tantas outras.

Não podemos, no entanto, esquecer que essa relação é tomada de modo dialético, uma vez que, mesmo os gêneros secundários alimentam-se dos primários. Bakhtin (2010 [1920-24]) propõe justamente que não se tome concretude e abstração como categorias de pensamento dicotômicas, visando uma relação ética do sujeito com o conhecimento produzido historicamente. Vigotski (2000 [1978]), ao discutir as relações entre 
aprendizagem e desenvolvimento, problematiza também, ainda que sob um olhar da psicologia da linguagem, o tensionamento entre conceitos espontâneos e científicos, considerando que é por meio da apropriação cultural pela linguagem que os sujeitos desenvolvem o pensamento, o que se dá justamente pela apropriação de conceitos relacionados às vivências cotidianas e de conceitos sistematizados, que nos levam a questionar e ressignificar nossas representações/interpretações de mundo. A língua, nesse contexto, é tomada como instrumento, como aquilo que se interpõe entre os sujeitos e o mundo, facultando a eles o conhecimento e reconhecimento da história e da cultura humana, de modo que se possa ressignificar e complexificar as produções decorrentes do trabalho humano na natureza e na realidade social (VIGOTSKI, 2000 [1978]).

Desse modo, ao propor um trabalho com a língua sob a perspectiva da análise linguística em um viés histórico-cultural e considerando os fundamentos do pensamento bakhtiniano, é preciso levar em conta que a leitura, a escuta e a produção de textos ancoram-se em uma concepção de sujeito e de língua que evocam discussões dos gêneros do discurso, de leitura e de escrita e oralidade que sejam convergentes com a base em questão. Abordar o texto é, nessas condições, abordar o texto na condição de enunciado, em conformidade com a realidade interacional da língua intermediadora das relações intersubjetivas, em contextos específicos, para finalidades discursivas determinadas.

A seguir, apresentaremos uma discussão acerca dos encaminhamentos metodológicos relativos ao trabalho com a análise linguística, ancorado em uma perspectiva enunciativista.

\section{Encaminhamentos de ordem metodológica}

Mediante a contextualização das diferentes acepções da análise linguística e de uma proposição de trabalho alinhada ao ideário histórico-cultural, nesta seção apresentamos as contribuições da opção teórico-metodológica por uma abordagem de análise linguística pautada nos fundamentos do pensamento do Círculo de Bakhtin. 
Lançaremos mão de uma estratégia que nos parece possível, considerando a compreensão de que o eixo de análise, de acordo com Mendonça (2006), pauta-se na reflexão explícita e sistemática da constituição e do funcionamento da língua em suas dimensões sistêmica, textual, discursiva e também normativa.

Nesses termos, a partir do trabalho com os processos envolvendo a leitura e a produção de textos orais e escritos, eixos do ensino de língua portuguesa em conformidade com os PCNs, apresentamos, com base em Cerutti-Rizzatti; Cassol Daga e Catoia Dias (2014), alguns encaminhamentos metodológicos que podem ajudar a pensar a análise linguística como estratégia ancorada em uma reflexão voltada para a ressignificação de representações/interpretações da realidade por parte dos alunos nas aulas de Língua Portuguesa, de modo que tais discussões sejam empreendidas em favor da formação de leitores e de produtores de textos na escola.

A respeito dessa questão, Cerutti-Rizzatti, Cassol Daga e Catoia Dias (2014) defendem que é papel dos professores de Língua Portuguesa educar a atenção dos leitores e produtores de textos orais e escritos no que concerne aos usos dos recursos linguísticos no âmbito da esfera em que estão se enunciando. Assim, não basta tomar a língua em sua dimensão sistêmica ou normativa, porque os sentidos dos diferentes usos relacionam-se às condições específicas em que tais usos se dão. Em se tratando dessa mesma questão, Britto (2012) aponta que a finalidade da escola é ampliar os conhecimentos dos sujeitos em relação à língua no bojo das práticas sociais, considerando valores e modos de organização das diferentes culturas, especialmente do tensionamento entre o que é local e o que é global, de modo que não se tome a escola como espaço do senso comum, mas que também não se ignore a relevância das relações estabelecidas pelos sujeitos na vida cotidiana. Ainda sob esse mesmo enfoque, o autor defende que a escola é lugar de promoção do senso crítico e de apropriação de conceitos sistematizados, visando, desse modo, o desenvolvimento intelectual de nossos alunos em uma perspectiva de formação integral do ser humano.

Importa situar ainda essa discussão em relação à compreensão de que a leitura e a produção de textos ancoram-se em uma articulação da dimensão intersubjetiva e intrassubjetiva e que tais processos se dão sempre em relação aos tipos relativamente 
estáveis de enunciados que se constituem a partir de um objeto e finalidade discursiva, de recursos linguísticos e de um acabamento vinculado à condição interlocutiva situada (com base em BAKHTIN, 2010 [1952-53]). Nesses termos, Cerutti-Rizzatti (2016) defende que a leitura não pode ser tomada assepticamente:

Uma abordagem histórico-cultural da leitura dissocia-se dessa intransitividade, entendendo que sujeitos corpóreos, historicizados nas relações intersubjetivas, leem textos em gêneros do discurso que facultam o estabelecimento de relações interpessoais em diferentes esferas da atividade humana. Logo, ler e leitura demandam necessariamente complementos, em comportamento forçosamente transitivo. Assim considerando, o papel da escola na apropriação da escrita como instrumento cultural, em se tratando dessa condição transitiva da leitura, implica promover encontros de leitores e diferentes autores, em seus projetos de dizer, com o fito de ampliar maximamente (com base em BRITTO, 2003; 2012) as intepretações da realidade natural e social dos sujeitos (com base em VOLOCHÍNOV, 2013 [1930]) exatamente nessas relações situadas com a alteridade.

Em relação à dimensão intersubjetiva tanto da leitura quanto da produção, importa levar em consideração que todo projeto de dizer situa-se no âmbito de uma esfera da atividade humana, em um determinado tempo-espaço, em um suporte específico. Em sentido de complementaridade defendido por Cerutti-Rizzatti, Cassol Daga e Catoia Dias (2014), a dimensão intrassubjetiva refere-se aos processos de construção de sentido por meio do mapeamento do conteúdo textual, considerando progressão e continuidade temática, relação estabelecida na concretização dos sentidos do texto; bem como de interpretação dos sentidos considerando ditos e subentendidos; além disso, trata dos recursos lexicais e gramaticais, bem como dos operadores argumentativos empreendidos em favor da produção ou depreendidos no processo de leitura.

Desse modo, pretendemos, partindo dos fundamentos que ancoram nossa ação, pensar o fazer da análise linguística considerando três objetivos de aprendizagem apresentados por Cerutti-Rizzatti, Cassol Daga e Catoia Dias (2014): enfoque na interação situada; articulação entre texto-enunciado e mundo vivido e tessitura linguístico-textual. 
As autoras propõem a complexificação dos objetivos de aprendizagem, mas enfocaremos apenas esses níveis por conta do recorte do gênero em que nos enunciamos.

Em relação ao enfoque na interação situada, as autoras tomam por base um olhar para a esfera, suporte, marcas linguísticas, interdiscursos (paráfrases, citações direta e discurso reportado), diferentes semioses e sequências textuais (narração, descrição, exposição, argumentação e injunção); em seguida, apresentam a articulação entre textoenunciado e mundo vivido, na qual propõem que se cotejem conhecimentos cotidianos, considerando a necessidade de se estabelecer conexões entre informações do textoenunciado e conhecimentos pouco familiares, bem como de compreender a complexidade implicada no domínio de conhecimentos especializados; por fim, a tessitura linguístico-textual implica conhecimentos relativos aos eixos de sentido, progressão temática, diferenciação entre fato e opinião, efeitos de humor, efeitos de sentido provocados pelas figuras de linguagem, relações de sentido envolvidas na seleção lexical (sinonímia, antonímia, homonímia, hiponímia, hiperonímia), efeitos de sentido decorrentes das variedades e diferentes registros, relações de causa e consequência e seu papel na tessitura textual, utilização de recursos lexicais e gramaticais voltados para a recuperação/progressão de referente, considerando categorias nominais e pronominais implicadas no processo de referenciação, reconhecer efeitos de sentidos pautados no uso de operadores argumentativos, bem como do papel das categorias adverbiais e adjetivas em relação à marcação de posicionamento e, enfim, identificar o papel das categorias verbais na construção do mundo narrado e comentado.

Assim, tomando tais objetivos e o trabalho a ser desenvolvido em relação à análise linguística numa perspectiva que se entende enunciativista de base bakhtiniana, lançamos mão de uma proposição de trabalho convergente com tal orientação teóricoepistemológica. Desse modo, considerando que as aulas de Língua Portuguesa envolvem a leitura, a produção de textos, a escuta, bem como a análise linguística em favor de tais eixos, importa levar em conta que, ao propor a entrada de textos em sala de aula, se pense e problematize a abordagem a ser empreendida, questão amplamente debatida por Geraldi (2010). Além disso, cabe lembrar que a leitura e a produção de textos se materializam sempre em determinados gêneros, o que quer dizer que o primeiro objetivo 
de aprendizagem proposto por Cerutti-Rizzati, Cassol Daga e Catoia Dias (2014) prevê que se traga para o horizonte dos alunos a identificação da esfera, do suporte, bem como de marcas linguísticas e discursivas que diferenciam um modo de organizar o dizer de outro.

Nessas circunstâncias, num trabalho que entendemos possível de ser desenvolvido em uma turma de nono ano, tomamos uma crônica de Verissimo (2010) para que possamos apresentar de modo contextualizado as possibilidades que podem emergir na dinâmica da leitura e da produção de textos, tendo a análise linguística como lugar de reflexão dos usos da linguagem em diferentes contextos. As razões da escolha desse texto, importa sublinhar, teriam de ser dar no vínculo com os processos pedagógicos mais gerais, tornando-se, assim, parte de um planejamento, de maneira que não se coloque como uma atividade isolada - tal proposição estaria vinculada a um trabalho mais amplo em torno da temática da desigualdade social no território brasileiro, considerando abordagens metodológicas voltadas para a prática social. Por conta do recorte necessário para os objetivos deste artigo, uma menção mais detalhada em relação às possibilidades de desenvolvimento desse planejamento não será feita; importa reiterar, entretanto, que compreendemos que quaisquer textos devem entrar na sala de aula na relação com os objetivos gerais e específicos delineados pelos docentes, bem como em se tratando dos conteúdos a serem abordados nesse processo.

Provocações

Luís Fernando Veríssimo

A primeira provocação ele aguentou calado. Na verdade, gritou e esperneou. Mas todos os bebês fazem assim, mesmo os que nascem em maternidade, ajudados por especialistas. E não como ele, numa toca, aparado só pelo chão.

A segunda provocação foi a alimentação que lhe deram, depois do leite da mãe. Uma porcaria. Não reclamou porque não era disso.

Outra provocação foi perder a metade dos seus dez irmãos, por doença e falta de atendimento. Não gostou nada daquilo. Mas ficou firme. Era de boa paz.

Foram the provocando por toda a vida.

Não pode ir à escola porque tinha que ajudar na roça. Tudo bem, gostava da roça. Mas aí lhe tiraram a roça. Na cidade, para onde teve que ir com a 
família, era provocação de tudo que era lado. Resistiu a todas. Morar em barraco. Depois perder o barraco, que estava onde não podia estar. Ir para um barraco pior. Ficou firme.

Queria um emprego, só conseguiu um subemprego. Queria casar, conseguiu uma submulher. Tiveram subfilhos. Subnutridos. Para conseguir ajuda, só entrando em fila. E a ajuda não ajudava.

Estavam lhe provocando.

Gostava da roça. O negócio dele era a roça. Queria voltar pra roça. Ouvira falar de uma tal reforma agrária. Não sabia bem o que era. Parece que a ideia era lhe dar uma terrinha. Se não era outra provocação, era uma boa.

Terra era o que não faltava.

Passou anos ouvindo falar em reforma agrária. Em voltar à terra. Em ter a terra que nunca tivera. Amanhã. No próximo ano. No próximo governo. Concluiu que era provocação. Mais uma.

Finalmente ouviu dizer que desta vez a reforma agrária vinha mesmo. Para valer. Garantida. Se animou. Se mobilizou. Pegou a enxada e foi brigar pelo que pudesse conseguir. Estava disposto a aceitar qualquer coisa. Só não estava mais disposto a aceitar provocação. Aí ouviu que a reforma agrária não era bem assim. Talvez amanhã. Talvez no próximo ano... Então protestou.

Na décima milésima provocação, reagiu. E ouviu espantado, as pessoas dizerem, horrorizadas com ele:

- Violência, não!

Novamente, no que tange à proposição de tal crônica, importa enfatizar que, em situação hipotética, ela está situada no planejamento docente e que, nesse contexto, é trazida para a sala de aula com o intuito de discutir com os alunos a temática do abismo social e da sociedade brasileira, considerando que é função da escola pôr em debate questões que transcendam o senso comum e que contribuam para o desenvolvimento intelectual e social dos estudantes (BRITTO, 2012). Nessas circunstâncias, ao trazer e apresentar um texto em determinado gênero, pensando na sistematização dos conhecimentos e no entendimento por parte do professor de que a educação linguística implica entender a língua como fenômeno histórico e complexo, mas vivo e em constante ressignificação (BRITTO, 2012; BAKHTIN, 2010 [1952-53]), o aluno precisa se situar em relação ao primeiro objetivo apresentado por Cerutti-Rizzatti, Cassol Daga e Catoia Dias (2014) - o enfoque na interação situada. Essa etapa da análise linguística abarca a relação do aluno com o texto-enunciado em uma dimensão extraverbal, cujo enfoque volta-se 
para o auditório e para a situação social, seja na leitura, seja na produção, ainda que o movimento se constitua de modos específicos em ambos os processos. Dessa maneira, tomando o enfoque na esfera, no suporte, na especificidade do dizer em relação ao conteúdo temático e ao acabamento do gênero, importa que se compreendam as relações intersubjetivas estabelecidas por meio da crônica: onde circula? Quem escreve crônicas? Por que as pessoas leem crônicas? Que especificidades apresentam? Que sentidos construímos a partir delas? Nesse ínterim, importa também compreender como a crônica é um gênero que tem estreito vínculo com a esfera jornalística, bem como a caracterização de Verissimo (2010), autor de relevante trânsito não só na literatura, mas principalmente em jornais e revistas do território brasileiro.

Em seguida, evocando o segundo objetivo, podemos pensar na articulação mais pontual entre o texto-enunciado e o mundo vivido, situando o aluno em relação aos conhecimentos trazidos por ele e outros conhecimentos necessários para que possamos compreender de modo mais efetivo os diferentes usos da linguagem e a relevância social de ampliarmos esses modos de dizer em conformidade com a situação em que um uso ou outro é requerido. Nesses termos, vale levar em consideração aqui que, de acordo com o pensamento bakhtiniano, aprender a usar língua é lançar mão de usos em conformação com a esfera e as condições vinculadas ao auditório e à situação, o que nos torna mais insiders ou mais outsiders em determinados contextos de uso da língua.

Em se tratando, então, dos dois objetivos apresentados, pode-se abordar em sala, por meio de atividades de compreensão do texto, ou tomando por base outros processos de sistematização do conhecimento, as informações apresentadas pela crônica e os conhecimentos do cotidiano, de modo a estabelecer um paralelo entre o provocado da crônica e os provocados de nossa comunidade, de nossa vida, e, nessa relação, promover uma discussão em torno dos sentidos possíveis para o próprio vocábulo provocação; em seguida, pode-se avançar nas questões elaboradas, solicitando que os alunos busquem entender situações que vão além do seu cotidiano, como, por exemplo, dados históricos relativos ao processo de organização da sociedade brasileira envolvendo o êxodo rural, e sua consequente relação com a exclusão e a desigualdade na atual configuração dessa sociedade. Ainda no que concerne aos dois objetivos de aprendizagem considerados, é 
interessante que os alunos sejam instigados a buscar por outras informações, outros dados históricos que os ajudem a compreender o teor da crítica de Verissimo (2010) na crônica supracitada, e é papel do educador intervir, por meio de questionamentos e de proposições de outras leituras, de maneira que eles estabeleçam as relações necessárias. Por conta do recorte deste artigo, não aprofundaremos as possibilidades dos encaminhamentos em sala de aula que pudessem levar o trabalho com a crônica a uma articulação com o tema desigualdade social na relação com a distribuição de terras, mas, reiteramos, tal narrativa pode ser destrinchada a partir de estratégias distintas, a depender, evidentemente, dos objetivos mais gerais delineados pelo docente.

Por fim, considerando o terceiro objetivo - tessitura linguístico-textual - e tomando por base os objetivos que antecederam o processo de compreensão da crônica proposta, passamos a questões mais específicas à dimensão verbal e ao sentido do texto na tensão com a dimensão extraverbal, uma vez que a língua integra a vida por meio de enunciados concretos e únicos e vice-versa (com base em BAKHTIN, 2010 [1952-53]). Nesse contexto, o desafio do professor passa a ser abordar o eixo de sentido sobre o qual os enunciados do autor se encadeiam, em um movimento de manutenção do mesmo tema e de progressão, o que exige que o docente elabore questões norteadoras do olhar do aluno em relação às categorias nominais e pronominais. $\mathrm{Na}$ crônica, podemos problematizar a partir das seguintes questões: i) A crônica 'Provocações' apresenta traços de narrativa e conta a história de um personagem genérico, mas muito específico. Por meio de quais recursos linguísticos podemos perceber essa relação?; ii) Luís Fernando Verissimo organiza a crônica em torno de uma série de provocações que aparecem marcadas em situações específicas. Que percurso o autor apresenta ao leitor para contar essa história?

Como podemos observar, a proposição de tais questões tende a levar o aluno a pensar sobre as escolhas linguísticas empreendidas pelo autor no momento da tessitura da crônica, atentando para os sentidos que deveria desencadear no seu leitor. Aqui, mais do que reconhecer e diferenciar um substantivo de um adjetivo, importa que o aluno compreenda os efeitos desencadeados pela seleção e disposição desses elementos em 
favor de uma entonação específica do projeto de dizer do autor (VOLOCHÍNOV, 2013 [1930]).

Outro objetivo-base tomado por Cerutti-Rizzatti, Cassol Daga e Catoia Dias (2014) refere-se ao papel das categorias verbais na construção do mundo apresentado pelo autor. No caso da crônica de Verissimo (2010), o professor pode chamar a atenção para o movimento desempenhado pela seleção dos tempos verbais em articulação com o uso de determinados advérbios. Como questão, poderíamos propor: iii) Em relação ao percurso tecido pelo autor, o eixo temático das provocações vai se concretizando até que o sujeito da crônica se reveste de esperança. No texto de Verissimo, como o uso dos verbos 'gostava', 'era', 'queria' e 'ouvira' e do advérbio ‘finalmente' dão contornos a essa ideia de esperança? A questão deveria desencadear uma reflexão acerca da característica narrativa do pretérito imperfeito e de uma mudança de tempo que se marca como ponto de virada no pretérito-mais-que-perfeito. De uma vida resignada a um momento de esperança, o personagem da crônica passa a agir e a pensar para além do destino que tinha sido reservado para ele até o momento em questão e o advérbio 'finalmente' aparece como um marcador de posicionamento axiológico-ideológico.

Em seguida, dando continuidade à progressão temática apresentada pelo autor, chamamos atenção para a importância da seleção lexical como outro objetivo apresentado pelas autoras: Verissimo (2010) coloca na história, ao lado dos verbos em pretérito perfeito, que marcam a determinação do personagem na busca por outro lugar - 'se animou', 'mobilizou', 'pegou', 'foi' -, a enxada como instrumento de trabalho e como arma para a luta. Tal tessitura nos possibilita a proposição da questão que segue: iv) Que papel a enxada tem na crônica? Que relações podemos estabelecer com a ação do sujeito do texto no mundo? A escolha, nesse sentido, da enxada, é fundamental para que a progressão e a manutenção do tema se articulem e para que o leitor evoque seus conhecimentos de mundo acerca da reforma agrária e das implicações dessa questão na sociedade.

Ainda em relação à articulação entre os objetivos de aprendizagem apresentados pelas autoras, podemos enfatizar os interdiscursos presentes no texto, dando destaque à voz marcada no discurso direto de um sonoro “- Violência, não”. A ironia, artifício usado 
comumente no gênero em questão, a qual se deixa entrever ao longo de toda a narrativa, materializa-se na voz oficial que aparece no texto por meio do travessão. Importa ressaltar que a ironia deve ser trabalhada pelo docente para que os alunos percebam como ela perpassa toda a tessitura da crônica, dando sentidos outros além daqueles da superfície, especialmente, neste caso, no que se refere à própria concepção e representação de violência em nossa sociedade. Como um dos objetivos deste trabalho deve estar relacionado à própria compreensão acerca da constituição do gênero crônica, torna-se imprescindível que tais aspectos sejam abordados - novamente, por conta do recorte a que nos propomos neste artigo, não verticalizaremos proposições em torno dos encaminhamentos possíveis no trabalho com a ironia presente no texto. Por meio da seleção desse recurso, é possível, por exemplo, explorar a questão do silenciamento de determinadas vozes em nossa sociedade, tratando do abismo social que se interpõe entre sujeitos advindos de determinadas histórias. Novamente, parece-nos interessante que o professor solicite ao aluno que mapeie no texto as denúncias apresentadas por Verissimo (2010) ao longo da narrativa. Poderíamos propor uma questão como a que segue: v) A crônica de Verissimo pode ser pensada como denúncia de um abismo social. Em que momentos do texto o autor aborda esse abismo? Apresente essas situações e comente, pensando no contexto brasileiro.

A crônica, publicada inicialmente em jornal ${ }^{2}$ e depois deslocada para outro suporte - questão a ser problematizada com os alunos -, aponta para diversos aspectos que podem ser abordados em relação aos objetivos apresentados por Cerutti-Rizzatti, Cassol Daga e Catoia Dias (2014). Não abordaremos todos, apesar de vislumbrar questões que articulam os três objetivos, tanto na leitura quanto na produção, que podem vir a ser consideradas no percurso do trabalho a ser realizado. No que tange à metodologia e à ancoragem teórico-epistemológica, buscamos, neste artigo, apresentar as convergências entre tais dimensões no que concerne aos pressupostos do ideário histórico-cultural.

\footnotetext{
${ }^{2}$ A discussão acerca da materialidade do gênero, em se tratando do suporte, retoma a relação com questões presentes no cotidiano as quais são fortalecidas pelo embate entre forças centrípetas e centrífugas, considerando o signo como fenômeno ideológico por excelência; e deslocadas em decorrência da marcação política, ideológica e axiológica do autor para uma grande temporalidade, o que se marca na publicação de tal crônica na obra referenciada aqui. Nesse contexto, faz-se necessário enfatizar o papel da autoria, em se tratando da concepção de sujeito tomada a partir da base históricocultural.
} 
Além disso, buscamos apresentar como a análise linguística pode ser pensada à luz do pensamento do Círculo de Bakhtin, considerando, então, as contribuições dos fundamentos propostos por esses autores.

\section{Considerações finais}

Empenhamo-nos, ao longo deste artigo, em discutir um dos eixos norteadores do ensino de língua portuguesa na Educação Básica do país, a análise linguística, num percurso que toma o conceito a partir das teorias já produzidas pela literatura da área, entendendo, pois, que deve ser compreendido como um processo de reflexão que terá o texto como ponto de partida e ponto de chegada, levando-se em conta a situação social de produção e de interlocução, o gênero selecionado, a seleção lexical, os mecanismos de textualização e as regras gramaticais necessárias para cada uma das situações de interação (COSTA-HÜBES, 2010). Este eixo norteador, assim, está ancorado na reflexão organizada, em favor da formação de leitores e de produtores de textos na escola (CERUTTI-RIZZATTI; CASSOL DAGA; CATOIA DIAS, 2014). O texto, neste sentido, é tomado na condição de enunciado, de forma que a língua é a mediadora das relações intersubjetivas entre aqueles que a utilizam, numa situação específica com finalidades também específicas.

A partir desta conceituação, foi nossa proposta aprofundar a sua compreensão, trazendo alguns dos fundamentos do Círculo de Bakhtin que embasam tal produção teórica, já que compreendemos que o trabalho com análise linguística numa perspectiva enunciativista - na sua intrínseca relação com os eixos de leitura e de produção textual será efetivamente compreendido e, então, sistematizado pelos professores de língua portuguesa, quando houver uma compreensão das bases que fundamentam o movimento que propõe que o ensino de língua se afaste de uma perspectiva voltada somente à gramática tradicional, em que as atividades metalinguísticas acabam por se sobrepor às epilinguísticas, e se aproxime disto que a literatura nomeia análise linguística e que foi o objeto de discussão deste trabalho. 
Entendemos, assim, que, ao propor o trabalho de análise linguística à luz do ideário histórico-cultural, temos necessariamente de considerar os sujeitos historicamente situados que fazem uso da língua, vivendo, agindo e se constituindo por meio dela, bem como a constituindo enquanto produto do trabalho humano. Ao considerar, então, a língua como lócus de interação, o trabalho docente não pode denegar aqueles que são os tipos relativamente estáveis de enunciados, os gêneros do discurso. Tal perspectiva, como buscamos deixar claro em nossas discussões, não omite o papel do sistema das formas linguísticas, no entanto, o estudo delas deve surgir em favor da ampliação dos usos da língua pelos alunos dos diferentes níveis escolares. Numa tentativa de materializar esta discussão teórica empreendida ao longo deste trabalho, apresentamos uma proposta de análise linguística a partir do gênero crônica como um exemplo de atividade que pode ser desenvolvida nas aulas de Língua Portuguesa, considerando o viés enunciativista discutido ao longo das seções.

Entendendo, no entanto, que o objeto deste artigo não se esgota com as contribuições apresentadas, sinalizamos a necessidade de aprofundamento e ampliação de discussões que contribuam com o desenvolvimento do trabalho docente no que se refere ao eixo da análise linguística nas aulas de Língua Portuguesa, por meio de teorizações em articulação com encaminhamentos metodológicos convergentes com fundamentos epistemológicos relacionados às concepções de sociedade, de ensino, de aprendizagem e de língua.

\section{Referências}

ANTUNES, Irandé. Aula de português: encontro \& interação. São Paulo: Parábola Editorial, 2003.

ANTUNES, Irandé. Análise de textos: fundamentos e práticas. São Paulo: Parábola Editorial, 2010. 
BAKHTIN, Mihkail. Filosofia do ato responsável. São Carlos: Pedro e João Editores, 2010 [1920-24].

BAKHTIN, Mihkail. Estética da criação verbal. 5. ed. São Paulo: Martins Fontes, 2010 [1952-53]. Bakhtin, 2010 [1979].

BAKHTIN, Mihkail. Problemas da poética de Dostoiévski. 2.ed. Tradução de Paulo Bezerra. Rio de Janeiro: Forense Universitária, 1997.

BEZERRA, Maria Auxiliadora; REINALDO, Maria Augusta. Análise Linguística: afinal a que se refere? São Paulo: Cortez Editora, 2013.

BRASIL. Ministério da Educação. Secretaria de Ensino Fundamental. Parâmetros curriculares nacionais: terceiro e quarto ciclos do ensino fundamental: língua portuguesa. Brasília: MEC/SEF, 106 p. 1998.

BRITTO, Luiz Percival Leme. Inquietudes e desacordos: a leitura além do óbvio. Campinas/SP: Mercado de Letras, 2012.

BRITTO, Luiz Percival Leme. A sombra do caos: ensino de língua x tradição gramatical. Campinas: Mercado de Letras, 1997.

CATOIA DIAS, Sabatha. Descrição e análise de concepções docentes referentes à leitura de professores do ensino fundamental de escolas estaduais do município de Florianópolis/SC. 2012. Dissertação (Mestrado em Linguística) - Universidade Federal de Santa Catarina, Programa de Pós-Graduação em Linguística, Florianópolis, 2012.

CERUTTI-RIZZATTI, Mary Elizabeth. A apropriação da escrita como instrumento cultural. In: CONGRESSO DE EDUCAÇÃO BÁSICA,VI, Florianópolis, 2016. Anais... Florianópolis: COEB, 2016. Disponível em:

<http://189.8.211.4/coeb2016/anais/conferenciasepalestras/mary.pdf >. Acesso em: 06.09.2017.

CERUTTI-RIZZATTI, Mary Elizabeth; DAGA, Aline Cassol; CATOIA DIAS, Sabatha. Intersubjetividade e intrassubjetividade no ato de ler: a formação de leitores na Educação Básica. Caleidoscópio, Unisinus, v. 2, n. 12, p.226-238, maio/ago 2014. Disponível em: <http://revistas.unisinos.br/index.php/calidoscopio/article/view/cld.2014.122.10>. Acesso em: 21 fev. 2016.

CORREIA, Karoliny. O Ato de dizer na esfera escolar: reverberações do ideário HistóricoCultural no ensino da Produção Textual Escrita. 2013. 386 f. Dissertação (Mestrado em Linguística) - Universidade Federal de Santa Catarina, Programa de Pós-Graduação em Linguística, Florianópolis, 2013. 
FARACO, Carlos Alberto. O estatuto da análise e interpretação dos textos no quadro do círculo de Bakhtin. In: GUIMARÃES, Ana Maria de Mattos; MACHADO, Anna Raquel; COUTINHO, Antónia. (Orgs.) O interacionismo sociodiscursivo: questões epistemológicas e metodológicas. Campinas/SP: Mercados da Letras, 2007, p. 43-50.

FARACO, Carlos Alberto. Linguagem e diálogo: as ideias linguísticas do Círculo de Bakhtin. São Paulo: Parábola Editorial, 2009.

GERALDI, João Wanderley (Org.). O texto na sala de aula. São Paulo: Ática, 2006 [1984].

GERALDI, João Wanderley (Org.). Portos de passagem. 4. ed. São Paulo: Martins Fontes, 2003 [1991].

GERALDI, João Wanderley (Org.). Ancoragens - estudos bakhtinianos. São Carlos: Pedro e João Editores, 2010.

GIACOMIN, Letícia Melo. Conhecimentos gramaticais na escola: 'regras' de um ensino sem regras. 2013. 274 f. Dissertação (Mestrado em Linguística) - Universidade Federal de Sata Catarina, Programa de Pós-Graduação em Linguística, Florianópolis, 2013.

MARCHIORO, Marina Zvierzikovski. A análise linguística e o texto dissertativoargumentativo: um olhar sobre o ensino de língua portuguesa. Revista Uniletras, Ponta Grossa-PR, v. 32, n. 1, p. 9-30, jan./jun. 2010.

MENDONÇA, Márcia. Análise Linguística no ensino médio: um novo olhar, um outro objeto. In: BUNZEN, Clécio; MENDONÇA, Márcia; KLEIMAN, Angela. Português no ensino médio e a formação do professor. São Paulo: Parábola Editorial, 2006.

SILVA, Noadia Íris da. Ensino tradicional de gramática ou prática de análise linguística: uma questão de (con)tradição nas aulas de português. Revista Brasileira de Linguística Aplicada, Belo Horizonte, v. 10, n. 4, p. 949-973, 2010.

TOMAZONI, Eloara. Produção textual na disciplina de língua portuguesa: concepções de professores de terceiro e quarto ciclos do ensino fundamental da rede estadual em santa Catarina. 2012. Dissertação (Mestrado em Linguística) - Universidade Federal de Santa Catarina, Programa de Pós-Graduação em Linguística, Florianópolis, 2012.

VERISSIMO, Luis Fernando. Mais comédias pra se ler na escola. Rio de Janeira: Objetiva, 2010.

VIGOTSKI. A formação social da mente. São Paulo: Martins Fontes, 2000 [1978]. 
VOLÓSHINOV, Valentín Nikoláievich. El marxismo y la filosofia del lenguaje. Buenos Aires: Ediciones Godot, 2009 [1929].

VOLOCHÍNOV, Valentin Nikolaevich. A construção da enunciação e outros ensaios. São Carlos: Pedro e João Editores, 2013 [1930]. 